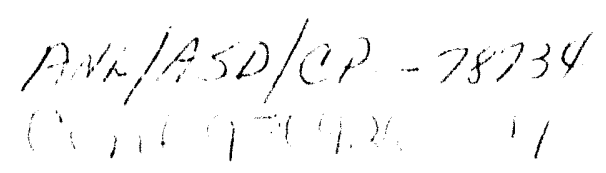

\title{
Performance of Quadrupole and Sextupole Magnets for the Advanced Photon Source Storage Ring
}

\author{
S. H. Kim, C. L. Doose, K. Kim, K. M. Thompson, and L. R. Turner \\ Argonne National Lahoratory \\ Argonne, Illinois 60439-4815
}

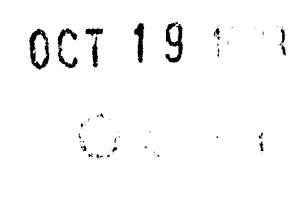

\begin{abstract}
From the magnetic measurement data of several production quadrupole and sextupole magnets for the storage ring of the Advanced Photon Source, the excitation efficiencies and systematic and random multipole coefficients of the magnets are summarized. The designs of the magnets, which are constrained due to the geometry of the vacuum chamber, have rotation symmetries of $180^{\circ}$ and $120^{\circ}$. The production data meet the allowed tolerances of a few parts in $10^{-4}$ for the storage ring.
\end{abstract}

\section{INTRODUCTION}

The 7-GeV Advanced Photon Source (APS), which is under construction at Argonne National Laboratory is a national facility dedicated to providing highly-brilliant synchrotron radiation beams [1]. The storage ring (SR) has a circumference of $1104.0 \mathrm{~m}$ with a 40 -sector Chasman-Green lattice to achieve a beam emittance less than $8.2 \times 10^{-9}$ $\mathrm{m} \cdot \mathrm{rad}$. The ring requires 400 normal quadrupole (quad) and 280 sextupole (sext) magnets for the control of the betatron oscillations and chromaticity of the positron beam. The required beam stay-clear aperture is $x= \pm 3.5 \mathrm{~mm}$ and $y= \pm$ $25 \mathrm{~mm}$.

Listed in Table 1 and Table 2 are the design parameters of

TABLE 1

MAIN PARAMITERS FOR TIIE SR QUAD MAGINETS

\begin{tabular}{|c|c|c|c|c|c|}
\hline & $Q_{1}$ & $Q_{2}$ & $Q_{3}$ & $Q_{4}$ & $Q_{5}$ \\
\hline \# Magnet & 80 & 80 & 80 & 80 & 80 \\
\hline$l(\mathrm{~m})$ & 0.50 & 0.80 & 0.50 & 0.50 & 0.60 \\
\hline$B^{\prime}(T / m)$ & -10.84 & 15.79 & -10.59 & -18.90 & 18.25 \\
\hline$B^{\prime} C(I)$ & .5 .42 & -12.63 & -5.29 & -9.45 & 10.95 \\
\hline $1(A)$ & 215 & 312 & 210 & 386 & 370 \\
\hline$L(m I)$ & 7.9 & 12.7 & 7.9 & 7.9 & 9.5 \\
\hline $\mathrm{R}(\mathrm{m} \Omega)$ & 29.5 & 44.0 & 29.5 & 29.5 & 340 \\
\hline Steel Mass (kg) & 1549 & 942 & 942 & 11,44 & \\
\hline
\end{tabular}

the conventional resistive quad and sext magnets for the SR. The 400 quads consist of five families with three different magnetic lengths; the four families of the 280 sext magnets

Manuscript received Seplemler 20, 1993. This work was supported by the U.S. Department of Energy, Office of Basic Energy Sciences, under Contract No. W-31-109-1ENC-38. have the same magnetic length. These magnets are excited by independent DC power supplies.

In spite of the conventional nature of the magnets, the designs of the magnet cross sections are severely constrained by the need to accommodate the vacuum chamber. Because of this requirement, rotation symmetries of $180^{\circ}$ and $120^{\circ}$ have been chosen for the quad and sext magnets, respectively, in order to minimize the undesired multipole field components. The design of the magnets and magnetic measurement data are described below. The allowed tolerances for the quad and sext are a few parts in $10^{-4}$ and $10^{-3}$, respectively.

TABLE 2

MAIN PARAMETIERS FOR THE SR SEXT MAGNLTS

\begin{tabular}{|c|c|c|c|c|}
\hline & $s_{1}$ & $\mathrm{~s}_{2}$ & $s_{D}$ & $s_{F}$ \\
\hline \# Magnet & 80 & 80 & 80 & 40 \\
\hline$l(\mathrm{III})$ & 0.2527 & 0.2527 & 0.2527 & 0.2527 \\
\hline $\mathrm{B}^{\prime \prime}\left(\mathrm{T} / \mathrm{m}^{2}\right)$ & 185.07 & -359.59 & -415.0 & 192.62 \\
\hline B"८ (T/m) & 44.72 & -86.30 & -99.59 & 46.23 \\
\hline$I(A)$ & 64 & 135 & 160 & 67 \\
\hline
\end{tabular}

For all sext magnets: Turns/coil $=42, \mathrm{~L}=17.2 \mathrm{mIl}, \mathrm{R}=107.5 \mathrm{~m} \Omega$, Stecl Mass $/$ Magnet $=405 \mathrm{~kg}$.

\section{DESCRIPTION OF THE MAGNETS}

All the quads have the same 2-D geometry and a bore radius of $40.0 \mathrm{~mm}$. The four sext families are the same design with a bore radius of $49.0 \mathrm{~mm}$. The magnet coils are watercooled copper conductor insulated with fiberglass or a preapplied polyimide/polyester/glass film and vacuumimpregnated epoxy. The cores of the magnets use $1.52-\mathrm{mm}$ thick laminations of low-carbon steel, coated on both sides

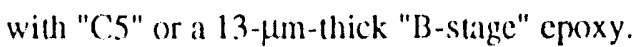

\section{A. Quadrupule Magnet}

The cross section of the quad with the vacuum chamber is shown in lig. 1. The top and bottom halves of the quad are not connected with flux-return yokes; they are comnected mechanically with aluminum spacers between the halves. bach of the top and bottom halves consists of two welded quadrant stacks. The weld joints have weld-relicf grooves to reduce the effects of weld shrinkage. Two fiducial hases for "CI:RN balls" are welded on top of the magnet. The magnet

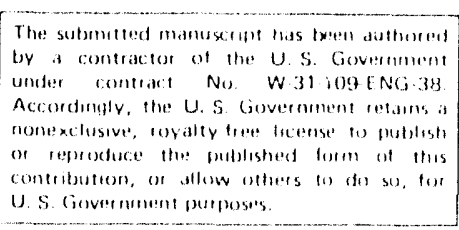


cores have alignment notches used for the attachment of a removable alignment fixture used for measurements of the magnetic axis and for the survey of the magnets in the SR.

In order to maximize the excitation efficiency, the pole $r(x) t$ ends are asymmetrically widened $22 \mathrm{~mm}$ towards the vertical plane of the magnet as shown in Fig. 1. By asymmetrically widening the poles, the efficiency for the $7-\mathrm{GeV}$ operation is greater than $95 \%$. The magnet has pole-end bevels of $9.6 \mathrm{~mm}$ $x 17.4 \mathrm{~mm}$ and pole chamfers of $16.5 \mathrm{~mm} \mathrm{[2].} \mathrm{The} \mathrm{shims} \mathrm{at}$ both edges of the hyperbolic pole face have 6-min-straight contours perpendicular to each other, and are used as the reference surfaces for stacking the laminations.

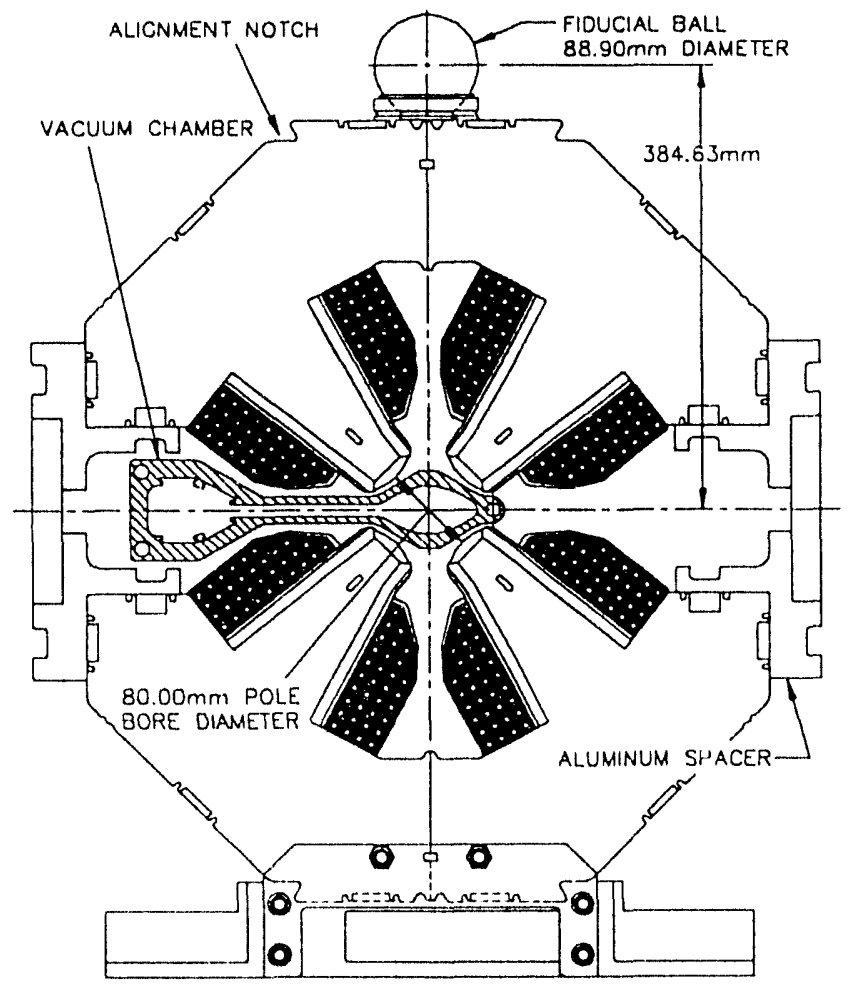

Fig. 1. Cross section of the SR quad with the vacuum chamber.

\section{B. Sextupole Magnet}

The cross section of the sext with the vacuum chamber is shown in Fig. 2. The magnet core is assembled from three identical stacks of laminations, each with two poles and a flux-return path joining them. The vacuum chamber extends into in one of the $102-\mathrm{mm}$ air gaps between neighboring stacks. At each end $12.7-\mathrm{mm}$-thick stainless steel plates hold the core sections in position; they are pinned and bolted to the core sections with an assembly fixture. The assembly of the magnet using the stainless steel plates is designed so that the upper two poles of the magnet core can be moved for installation of the vacuum chamber. A fixture with two fiducial bases is installed on top of the magnet.

Since the length of the magnet core is relatively short compared to the dimensions of the cross section of the magnet, extensive magnetic field computations were carried out for the 2-D as well as 3-D geometries using the codes PE2D and TOSCA [3]. The computed data for the 18-pole coefficient $b_{8}$, defined in the following section, agree with the measurements within $0.5 \times 10^{-4}$.

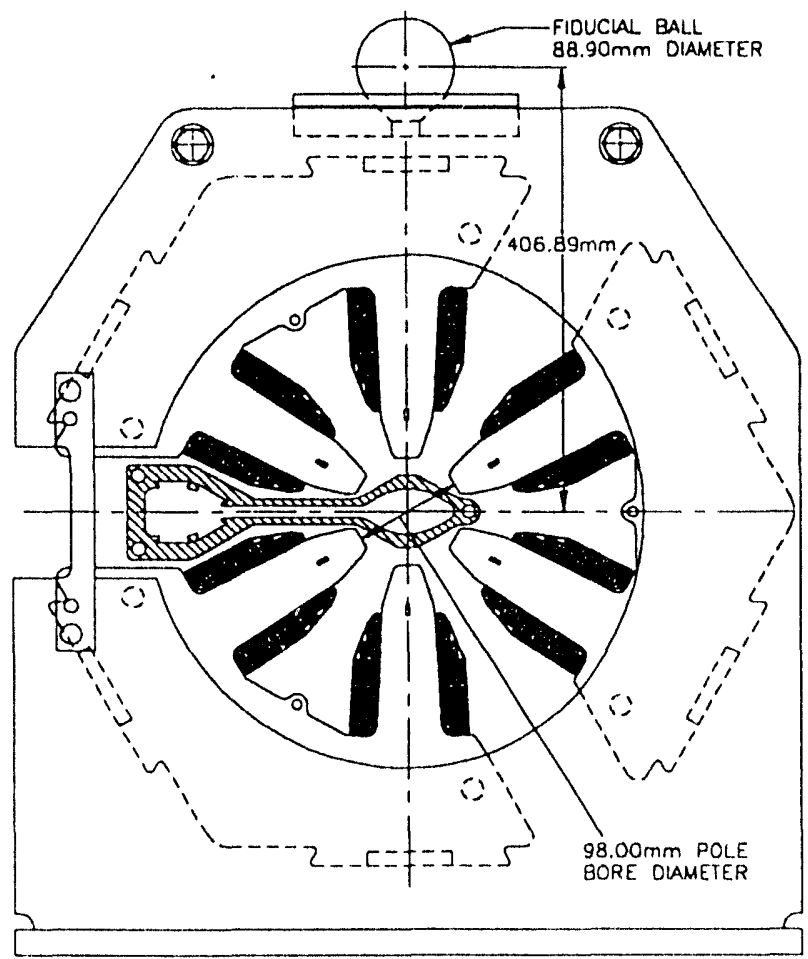

Fig. 2. Cross section of the SR sext with the vacuum chamber. A renovablo fiducial ball base is shown on top of the magnet.

\section{MAGNETIC MEASUREMENTS}

The integrated and 2-D fields, and multipole coefficients are measured using a rotating coil technique. The probe coil consis. of "radial" and "tangential" coils on the same cylinder [4]. The 2-D "body" fields are measured using "short" tangential coils. The normal and skew multipole field coefficients, $b_{n}$ and $a_{n}$, for a 2-D magnetic field, $B=B_{y}+$ $i B_{x}$, are detined

$$
B C=B_{0} C \sum_{n=1)}^{\infty}\left(b_{n}+i a_{n}\right)\left[(x+i y) / r_{0}\right]^{n},
$$


where $\ell$ is the magnetic length for an integral measurement and the reference radius $r_{0}$ is $25 \mathrm{~mm}$. The coefficients are defined as $b_{1}=1.0$ and $a_{1}=0$ for $a$ quad, and $b_{2}=1.0$ and $a_{2}=$ 0 for a sext magnet.

The axis of the rotating coil is aligned to the magnetic axis by adjusting the magnet position to where the dipole and quad field components of the quad and sext magnets, respectively, vanish. Prior to this procedure, for the quad magnet only, the bore axis of the quad is aligned to the axis of the two airbearings defining the axis of the rotating coil by the following method. A laser beam unit is installed and aligned with the axis of the air-bearing. A photo-quadrant detector is placed at the bore axis of the magnet aperture. After detecting the beam position along the bore axis, the magnet position is adjusted to align the bore axis to the laser beam. This procedure not only ensures parallelism between the bore and magnetic axes to at least $\pm 0.2 \mathrm{mrad}$, but it also enables measurement of the offset of the two axes.

In Fig. 3 the integrated and 2-D "body" field-gradients, normalized to the values at $160 \mathrm{~A}$, are plotted against the excitation current. The data show that the efficiencies up to the excitation current of $380 \mathrm{~A}$ are higher than $95 \%$, and the difference between the values of the integrated and 2-D gradients are approximately $1 \%$.

Similarly, the efficiency for the sext is plotted in Fig. 4. The 2-D data are taken using a $0.1-\mathrm{m}$-long tangential coil. $\mathrm{Al}$ $150 \AA$, the efficiency for the integrated sext strength is $97 \%$ and its $2-\mathrm{D}$ value is $1 \%$ higher.

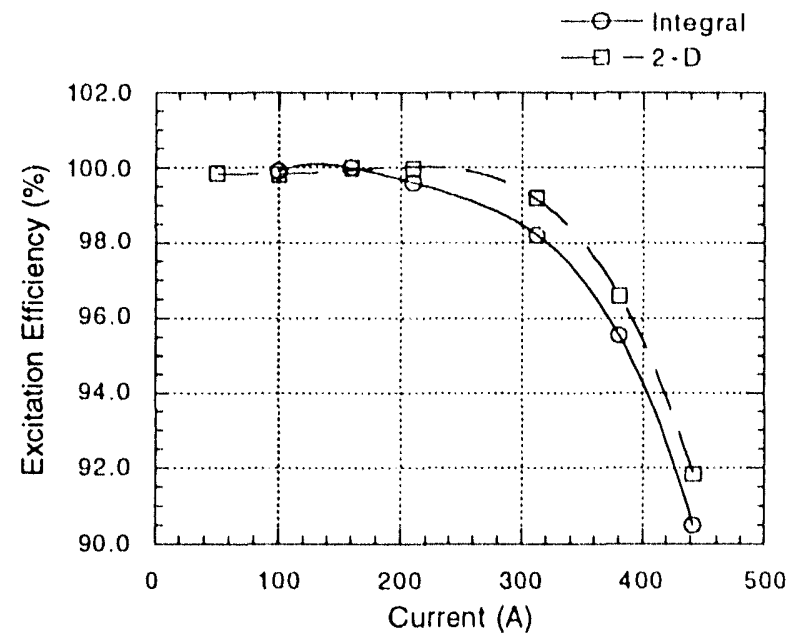

Fig. 3. The integral and 2-D excitation efficiencies of the SR quad. The data at $160 \mathrm{~A}$ are used as $100 \%$ efficiency.

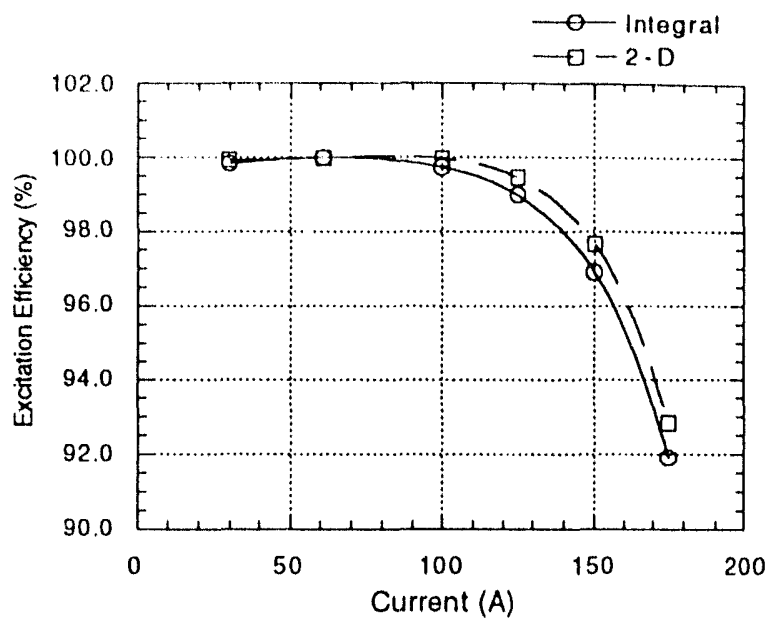

Fig. 4. The integral and 2-D excitation efficiencies of the SR sext. The data at $60 \mathrm{~A}$ are used as $100 \%$ efficiency.

Plotted in Fig. 5 are the systematic (average) and random (rms) multipole coefficients for the first 20 production quads. Cofficients less than $1 \times 10^{-4}$ are included in the figure. Variations of the systematic coefficients at the three excitation currents less than $1 \times 10^{-4}$ are due to the ambient field and iicld saturation at the poles. Similarly, the systematic and random coefficients for the first six sexts are shown in Fig. 6.

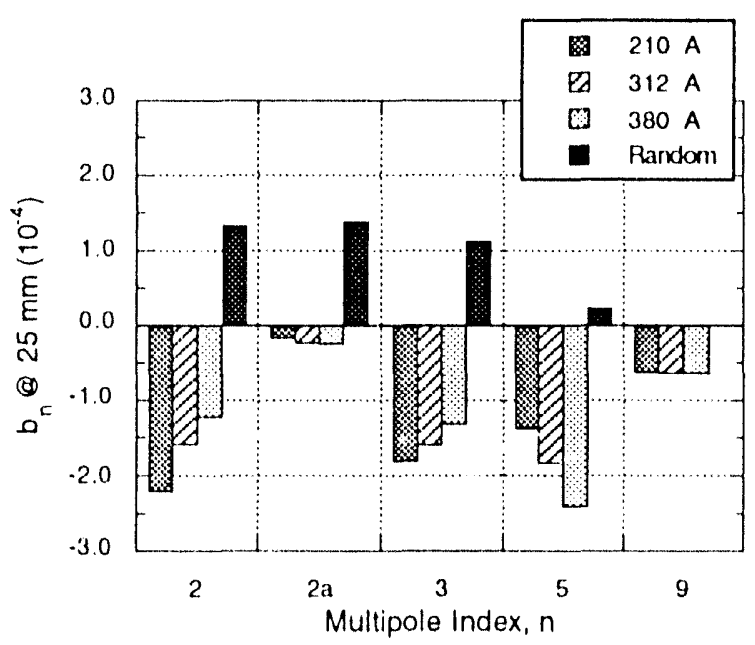

Fig. 5. Systematic at three excitation eurrent: and random multipule coreficients for the first 20 production quads at thee excitation currents. Mulfipole index 2 a stands for the skew sextupele cerfficient. The randent coefficients are independellt of the currents. 


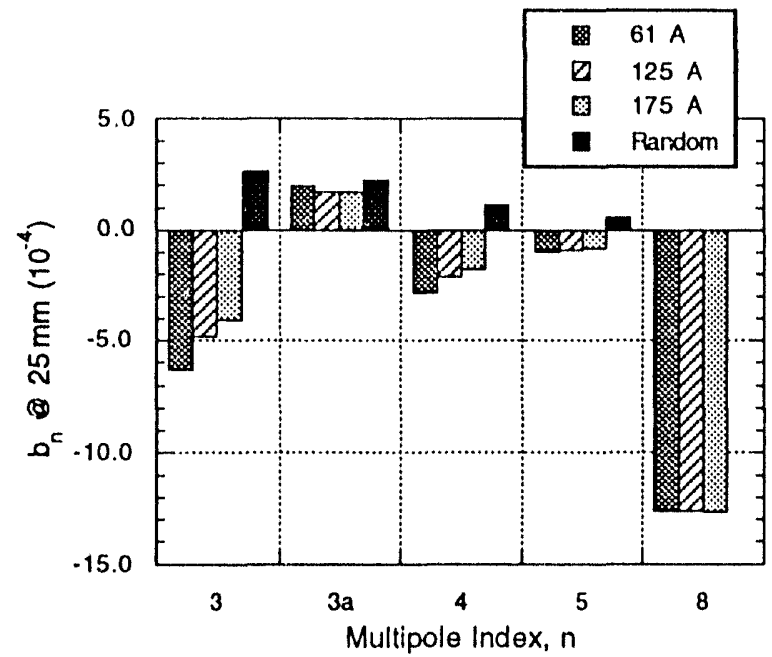

Fig. 6. Systematic at three excitation currents and random multipole coefficients for the first six production sexts at three excitation currents. Multipole index 3a stands for the skew octupole coefficient.

\section{SUMMARY}

The data of the magnetic performances, measured from the first 20 quad and 6 sext production magnets, meet the allowed tolerances and are summarized in Table 3. The random multipole coefficients for the 20 quads are less than $1.5 \mathrm{x}$ $10^{-4}$, which indicates that the assembly procedure for the quad is relatively consistent. In spite of the design constrains of the magnets, the efficiencies for 7-GeV operation are higher than $95 \%$.
TABLE 3

TOLERANCE AND MEASURED RMS FOR THE SR QUAD AND SEXT MAGNETS

\begin{tabular}{|c|c|c|c|}
\hline & & $\begin{array}{l}\text { Allowed } \\
\text { Tolerance }\end{array}$ & $\begin{array}{l}\text { Measured } \\
\text { rms }\end{array}$ \\
\hline \multirow[t]{3}{*}{ Quad } & $\left.<\triangle B^{\prime} C / B^{\prime} C\right\rangle$ & $5.0 \times 10^{-4}$ & $3.0 \times 10^{-4} *$ \\
\hline & $b_{2}$ & $2.5 \times 10^{-4}$ & $1.3 \times 10^{-4}$ \\
\hline & $\mathrm{b}_{3}$ & $3.1 \times 10^{-4}$ & $1.2 \times 10^{-4}$ \\
\hline \multirow[t]{2}{*}{ Sext } & $<\triangle B^{n} C B^{n} C>>$ & $2.5 \times 10^{-3}$ & $1.0 \times 10^{-3} *$ \\
\hline & $\mathrm{b}_{3}$ & $3.1 \times 10^{-3}$ & $2.6 \times 10^{-4}$ \\
\hline
\end{tabular}

*Accuracies for individual magnet measurements.

\section{REFERENCES}

11] "7-Gev Advanced Photon Source, conceptual design report," Argonne National Laboratory, ANL-87-15, 1987.

(2) S. 11. Kin, K. M. Thompson, E. L. Black and J. M. Jagger, "Fabrication and tests of prototype quadrupole Magnets for the storage ring of the Advanced Plioton Source," Conf. Proc. of the 1991 IEEE Particle Acc. Conf., Vol. 4, pp. 2375-2377, 1991.

(3) L. R. Turner, K. M. Thompson, S. H. Kim and K. Kim, "Design and measurement of the sextupole magnet for the APS storage ring," Proc. of the Particle Acc. Conf., Washington, DC, May 1993.

[4] S. H. Kim, C. Doose, R. Hogrefe, K. Kim, and R. Merl, "The magnetic measurement facility for the Advanced Photon Source," in these proceedings.

\section{DISCLAIMER}

This report was prepared as an account of work sponsored by an agency of the United States Government. Neither the United States Government nor any agency thereof, nor any of their employees, makes any warranty, express or implied, or assumes any legal liability or responsibility for the accuracy, completeness, or usefulness of any information, apparatus, product, or process disclosed, or represents that its use would not infringe privately owned rights. Reference herein to any specific commercial product, process, or service by trade name, trademark, manufacturer, or otherwise does not necessarily constitute or imply its endorsement, recommendation, or favoring by the United States Government or any agency thereof. The views and opinions of authurs expressed herein do not necessarily state or reflect those of the United States Government or any agency thereof. 

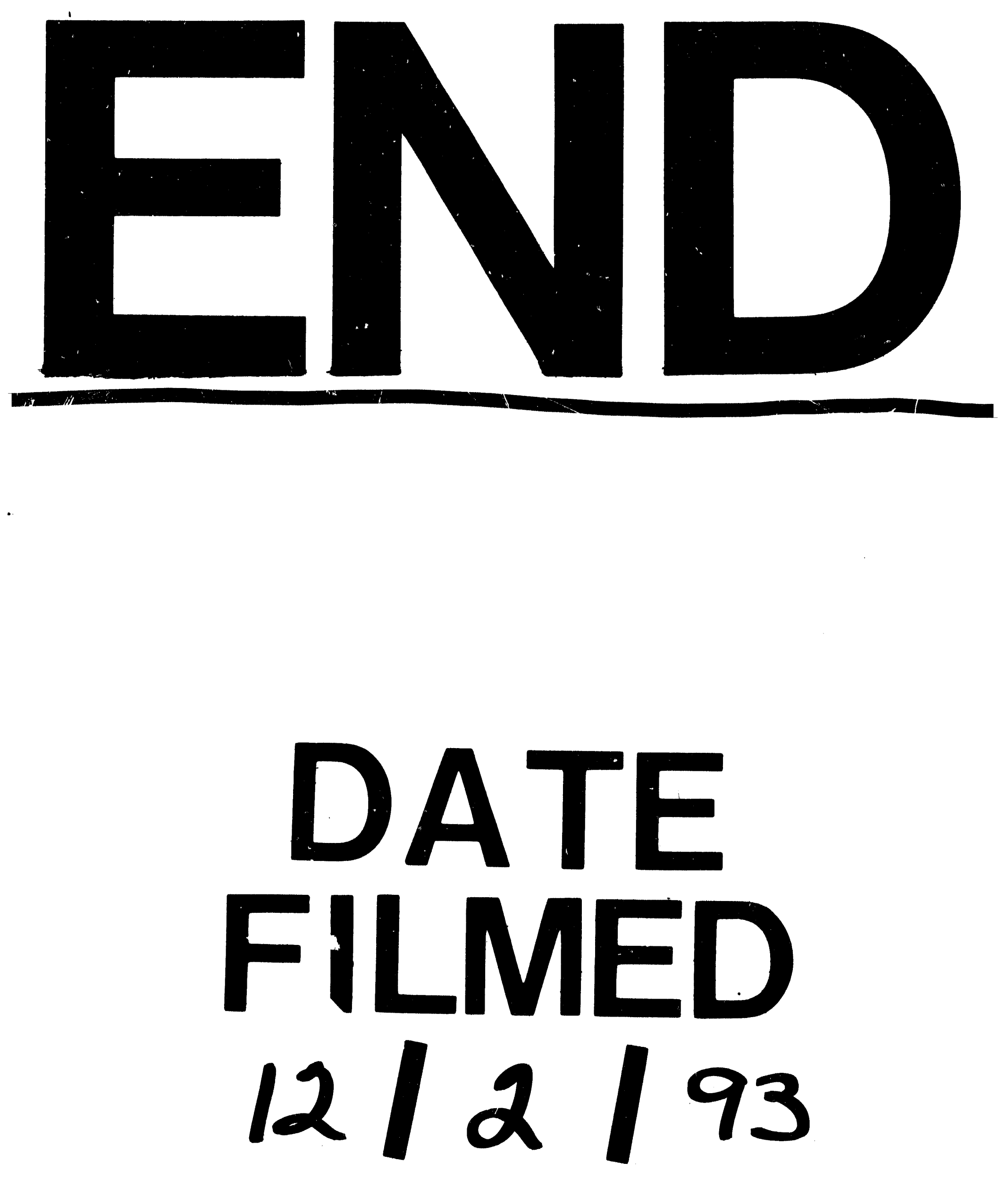
